JED

23,2

Received 28 August 2020

Revised 2 November 2020

Accepted 5 December 2020

\section{Exploring the magnitude of inclusion of Indian youth in the world of work based on choices of educational attainment}

\author{
Nitin Bisht and Falguni Pattanaik \\ Department of Humanities and Social Sciences, \\ Indian Institute of Technology Roorkee, Roorkee, India
}

\begin{abstract}
Purpose - This study attempts to investigate the interrelationship between choice-based educational achievement and employability prospects across the skill-based occupations amongst the youth in India.

Design/methodology/approach - This study relies on the use of National Sample Survey (NSS) data on employment and unemployment for the 68th round (2011-2012) and the Periodic Labour Force Survey (PLFS) (2017-2018). To estimate the relative contributions of choice-based educational attainment affecting the skillbased employment of youth in a different category of occupations ( high/medium/low skilled), the multinomial logistic regression and its marginal effects have been used.

Findings - The study finds educational attainment both as an opportunity (improvising employability in the high and medium skill occupation) and a challenge (highest unemployment amongst the educated) while ensuring skill-based youth employability. Despite the growing enrolment of youth in education, youth from a general education background does not find sustained employability prospects in high-skill occupations.

Research limitations/implications - Vocational education highlights a brighter employability prospect but the acceptability of the same amongst the youth needs a policy intervention.

Practical implications - Educational choices need an intervention based on market-driven apprenticeships and training.

Social implications - The decline of overall employability in the low-skill occupation raises a threat to inclusive development as such youth results to Not in Employment, Education or Training (NEET), better identified as the unproductive economic youth.

Originality/value - This study attempts to investigate that "how far the choice of educational attainment (general/technical/vocational) is able to make youth a fit in the world of work?" in the Indian context, where the youth constitute the highest share in the population.
\end{abstract}

Keywords Education, Employability, School-to-work transition, Skill occupations, Youth

Paper type Research paper

\section{Introduction}

The youth represent the most potential workforce at the meso (individual and family levels), micro (societal level) and the macro (country level) strata of economic development. However, channelizing that potential requires a significant relationship between the educational attainment and the "world of work". The education and skills serve as substantial indicators of youth employability in the labour market (Aggarwal and Gasskov, 2013). On the one side, education enhances learning and nurtures skills to improvise youth employability. On the

(C) Nitin Bisht and Falguni Pattanaik. Published in Journal of Economics and Development. Published by Emerald Publishing Limited. This article is published under the Creative Commons Attribution (CC BY 4.0) licence. Anyone may reproduce, distribute, translate and create derivative works of this article (for both commercial and non-commercial purposes), subject to full attribution to the original publication and authors. The full terms of this licence may be seen at http://creativecommons.org/licences/by/4.0/ legalcode

Funding: The authors received no financial support for this research manuscript.

Declaration of conflicting interests: The authors declared no potential conflicts of interest for the research study, authorship and publication of this article. 
other hand, the learning and skills enable youth to fit in the "World of Work" - if only, skills find a relevant match with the demand side of the labour market.

Due to a noticeable difference between the educational attainment and the skills requirement of the labour market, the United Nations (UN) identifies employability both as "opportunity" and "challenge" (McQuaid and Lindsay, 2005). Apart from education and skills, certain supply side factors of the labour market such as age (Purcell et al., 1999), gender (Brooks, 1997) and social class (Brennan, 1996) also embrace an equal contribution in defining the employability of the younger generation (Pool and Sewell, 2007).

The concept of employability is not new in the "world of work"; however, it has witnessed a continuous change with the change in the demand side of the labour market. Employability reflects a multifaceted concept, which frequently changes with demand and is therefore hard to measure (Guilbert et al., 2016). However, the core concept of employability highlights the essential capabilities of an individual required to acquire, sustain and gain employment (Hillage and Pollard, 1998). The employability aspect largely depends on the labour market functioning and the economic health of the country (Brown et al., 2003).

However, counter studies argue that while addressing youth employability, youth expectations are neglected (Artess et al., 2017) and the focus remains limited to the only demand side prospects (Artess et al., 2017). With the fast pace of technological upgrade, the employability for skilled workforce in the labour market has increased globally (Taylor, 2005). Moreover, the growing demand for skills has affected the employability of the educated younger generation. The delayed employability increases the risk factor for educational achievements to become obsolete in the labour market.

The wide gap between demand (labour market) and supply (education and skills) forces educated youth to compensate with the low-skilled jobs, creating a "crowding out" effect - a phenomenon when a highly educated youth compromises with under-skilled jobs at the cost of less-educated counterparts (Hansson, 2007). The aspect reflects the missing "shool-to-work" transition of youth.

Since the employment status serves as a proxy for employability (Dibeh et al., 2019), this study attempts to analyse the employability status of youth in a different category of occupations (high/medium/low skilled), considering their educational choices/attainments. The novelty of this study adds value to the limited studies on youth in India and estimates the relative contributions of streamwise educational attainment affecting youth employability. This study is one of its kind to utilize the latest youth employment and unemployment data available in the Indian context to address the nexus of youth inclusiveness in education versus their inclusivity in the labour market. For this, the next section provides a brief review of the literature, followed by the data and the methodology. While the results and discussions, followed by a conclusion are presented after that.

\section{Literature review}

Education reflects the supply side perspective, while the employability gets derived from the demand side of the labour market. At the individual level, education remains one of the significant modes of enhancing employability opportunities in the labour market (Krishnakumar and Nogales, 2020). Studies have observed that with an increase in the education level, employability perspective also increases (Arrow, 1973). The level of educational attainment creates a unique identity for an individual in the labour market, especially for the youth, represented as the newbies of the labour market due to lack of work experience (Bisht and Pattanaik, 2020). The significance of education in the "world of work" is highlighted through the global expansion of higher education; however, the educational expansion witnesses a continuous challenge of meeting the future employability demand of the labour market.

Moreover, prolonged education tenure and lack of a demand-led education system also hinder the youth employability. The education level highlights the learning of an individual

\section{Choices of educational attainment}


JED

23,2

depicted through the accumulation of knowledge and skills (Kyndt and Baert, 2013). However, learning alone does not compulsorily guarantee the upgrade of skills required to fit through the lens of employability as per the demand of the labour market (Fasih, 2008). According to Chevalier and Lindley (2009), attainment of educational achievements but lack of labour market-driven skills creates the burden of an overeducated populace on the economy. Moreover, Dunne et al. (2000) have argued for establishing a timely communication between the higher education institutions and labour market functioning to enhance the employability prospect.

Education does perform the role of enabling factor for youth to enter the labour market. However, meeting the labour market demand remains a challenge to ensure employability. The employability of the highly educated youth reflects the utmost difficulty as there are chances that their educational achievements may not meet the existing demand of the labour market. On the contrary, the labour market may find the less educated youth suitable to perform the jobs at a lower wage rate, thereby creating an invisible effect on the employability of the highly educated youth. However, the utility of education to derive the youth employability exists undoubtedly in the "world of work".

\subsection{Education, skill mismatch and employability amongst youth in India}

With the advent of liberalization in the year 1991, the Indian labour market is supposed to play an active role in improvising employability opportunities for the growing share of youth (aged 15-29 years) population. Having witnessed the economic development of the East Asian Tiger countries, as a result of investment in their youth human capital at the time of their "Demographic Dividend", the same is expected to work for the Indian scenario (Mitra and Verick, 2013). However, despite the highest share in the total population of the country, the Indian youth suffers from an all-time highest unemployment rate of $17.8 \%$ (Periodic Labour Force Survey, 2017/18). Studies highlight that unemployment due to skill mismatch reflects the structural form of unemployment (Singh, 2003) and questions the interrelationship of the education system, labour market and the economy (Mehrotra et al., 2013). The inability of the educational qualifications to match the skill requirements of the labour market remains a significant challenge (Okada, 2012).

The quantification of educational institutions in the early 2000s resulted in the fast pace of youth enrolment in higher education. However, the upward mobility of the educational attainment served as a risk factor for the youth employability in the "world of work" (Agarwal, 2008). The highly educated individuals are more vulnerable in terms of employability in the labour market (Sharma and Sharma, 2017). Studies have observed skill mismatch as one of the significant aspects of reducing the employability of educated youth in the labour market (Dev and Venkatanarayana, 2011).

The early drop out of youth from education results in the skill mismatch and acts as the contributing factor for hindering youth employability. The decision of youth to continue in education depends on sectoral characteristics as the urban sector youth enjoys a comfortable and frequent education-to-work and work-to-education switching. However, youth leaving education at an early stage in the urban sector remains engaged as casual labour (Mitra and Verik, 2013). Moreover, expanded educational level amongst the rural youth served as a contributing factor in driving rural youth towards selfemployment or self-entrepreneurship activities such as horticulture, dairy farming and poultry (Bhanwala and Mani, 2020).

Educational development in the country has increased educational choices for the younger generation. However, despite education, specific socio-economic characteristics also hamper the economic productivity of the younger generation. According to Sanghi (2012), a substantial discrepancy based on the gender, sector and educational attainment prevails in 
the youth labour market. Further, educational expansion in India still seems to fight with the socio-economic constraints in terms of defining youth employability. These invisible forces of the Indian society restrict opportunities for youth employment. The non-inclusion of youth in higher education based on the caste, class, gender and region aspects calls for a threat to the inclusiveness of expanding higher education (Tilak, 2015).

The number of educational setups, along with enrolment of the younger generation in higher education, has increased over the last decade (MHRD, 2019). While on the other side, lack of labour market-driven skills amongst the educated youth has negatively affected their employability (Wheebox, 2020). However, studies have argued that the quest for employability skills amongst educated youth always remains a challenge (McQuaid and Lindsay, 2005) for developing economies like India. Henceforth, the employability issue amongst the educated youth as compared to the lower qualified or illiterate counterparts raises a concern for the Indian economy. Based on the above-discussed literature, this study proposes the conceptual framework (see Figure 1) highlighting the supply side challenges towards ensuring the youth employability in India.

\section{The database and the methodology}

\subsection{The database}

This study relies on the use of National Sample Survey (NSS) data on employment and unemployment for 68th (2011-2012) round and the Periodic Labour Force Survey (PLFS) (2017-2018). The workforce participation and unemployment rates are estimated using the UPSS (principal status + subsidiary status) approach. The NSS defines the UPSS approach as a combination of principal status, in which an individual spent longer duration during the 365 days reference period before the survey and the subsidiary status in which an additional activity is undertaken for 30 days or more by the individual whose principal status is determined during the reference period of 365 days. Considering the UPSS approach, the occupation wise (National Classification of Occupation (NCO), 2004) youth employment is

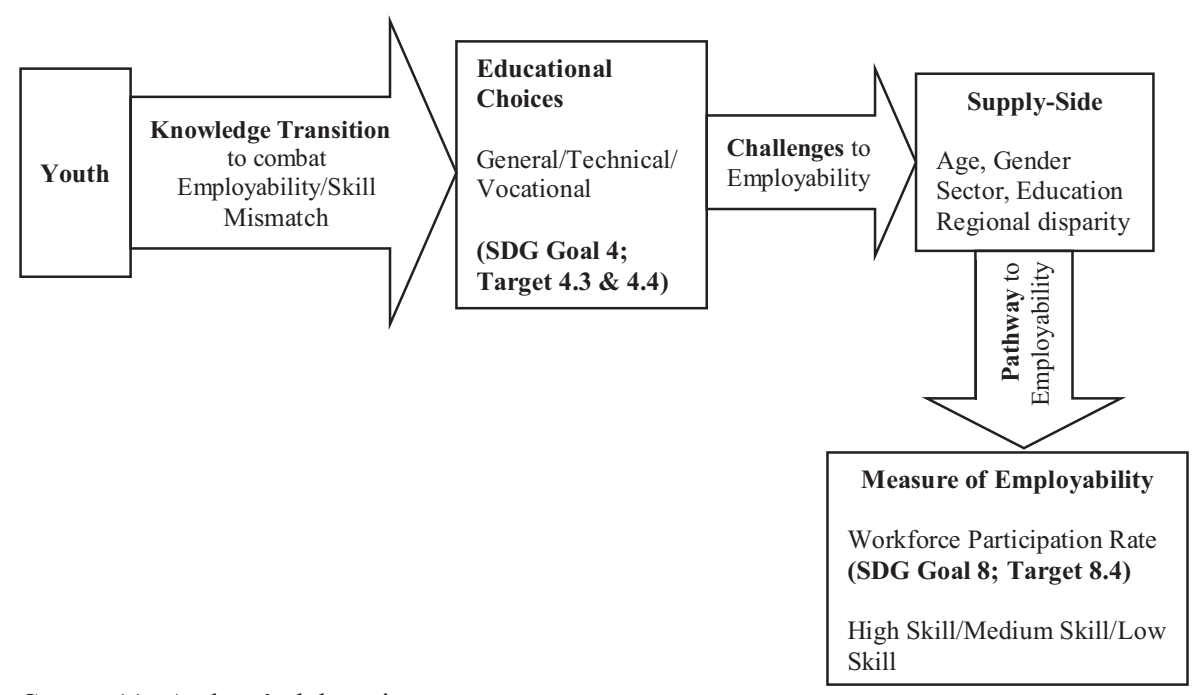

Choices of educational attainment

Source(s): Authors' elaboration

Figure 1.

The conceptual framework: youth course of employability 
categorized into skills (high/medium/low) by using the International Classification of Occupation.

\subsection{The methodology}

Intending to estimate the likelihood of educational attainment in ascertaining the employment status, this study implicates the use of multinomial logit regression. The multinomial logit regression finds its utility in labour studies while estimating the effect of socio-economic indicators on directing an individual's employability with more than two categories of dependent variable (Poterba and Summers, 1995; Denny and Harmon, 2000; Kucharski and Kwiatkowski, 2006). The dependent variable is the workforce participation rate (WPR) and highlights the employment status of youth. The employment status has been further categorized into the high, medium and low skills based on the NCO (2004). The equational representation of the logit function is represented as follows:

$$
\log i t\left(\pi_{i j}\right)=\log \left[\pi_{i} /\left(1-\pi_{i}\right)\right]=\beta_{0}+\beta(X)+\varepsilon
$$

This study estimates the beta coefficients of the outcome variables with the highly skilled workforce as the reference category by using the multinomial logit, which in the equation form is represented as follows:

$$
\begin{gathered}
Z_{1}=\log Z\left(\frac{Y_{2}}{Y_{1}}\right)=a_{1}+\sum b_{i j} * X_{j} \\
Z_{2}=\log Z\left(\frac{Y_{3}}{Y_{1}}\right)=a_{2}+\sum b_{i j} * X_{j} \\
Y_{1}+Y_{2}+Y_{3}=1
\end{gathered}
$$

where

$$
\begin{aligned}
& a_{i}, a_{2}=\text { constant; } \\
& b_{i j}=\text { multinomial regression coefficient }(i=1,2,3 ; j=1,2, \ldots, n) ; \\
& Y_{1}=\text { high skill (reference category); } \\
& Y_{2}=\text { medium skill; } \\
& Y_{3}=\text { low skill }
\end{aligned}
$$

This study further estimates the marginal effects to highlight the individual impact of the independent variables (Wooldridge, 2002) on the overall change in the employability of the youth. Despite the base outcome, the marginal effects are considered an appropriate statistical tool for the analysis (Mahapatro, 2019).

The equational representation of the marginal effect is expressed as follows:

$$
\begin{aligned}
& \text { MarginalEffect }\left(\operatorname{ME}\left(X_{1}\right)\right)=\frac{\partial Y}{\partial X_{1}}=f_{1}^{\prime}(X)=g_{1}(f(X)) \\
& \text { Marginal Effect }\left(\operatorname{ME}\left(X_{n}\right)\right)=\frac{\partial Y}{\partial X n}=f_{n}^{\prime}(X)=g_{n}(f(X))
\end{aligned}
$$

The independent variables include the supply side challenges to employability, namely, age, sex, sector, education categorized as the general, technical and vocational and state-regions. 


\section{Results and discussions}

\subsection{Paradox of educational choices/attainment and youth employability}

Studies opine that improvising youth employability is not only an indication of the country's progression but also a measure of the strengthened education system (Smith et al., 2000). Despite significant economic growth, the youth labour market in India witnesses the paradox of increasing educated youth but shrinking regular employment opportunities. The declining trends of employability create a debate on the policy front as the Indian economy is not able to utilize its ongoing "demographic dividend" transition. The study observes a substantial increase in the enrolment of male as well as female youth in higher education from 2011-2012 to 2017-2018 (see Figure 2).

The female youth reflects higher enrolment as compared to male counterparts. The pattern demonstrates access of female youth to higher education; however, inclusiveness of female youth in the labour market remains an issue. Moreover, due to shrinking employment opportunities, male youth chooses to stay in the labour market compromising with low or substandard jobs. On the contrary, unless burdened by compulsion, female youth opts to continue with higher education, with a notion of improvising employability opportunities with an increase in their educational hierarchy.

Apart from the macroeconomic perspectives, employability gets affected by the individual characteristics too. The overall employability in the high- and medium-skill occupations has shown an increase of $2.6 \%$ points and $3.1 \%$ points, respectively, over the period $2011-2012$ to 2017-2018 (see Table 1).

On the contrary, employability in low-skill occupation declines by $5.7 \%$ points during the study period. However, the decline in low-skill occupation represents a dual-side debate. First, the ongoing educational expansion in the country might have enabled the capacity of the younger generation to find themselves a suitable fit in the high- and medium-skill occupations. Secondly, low-skill occupation might have suffered from the shrinking employment opportunities, forcing a large share of unskilled youth towards NEET .

Age significantly defines the youth labour market entry. Ideally, the significance of age relates to the completion of school education (15-19 years), coupled with skill enhancement and capacity building if one continues up to higher education (20-24 years) and then after entry in the "world of work" (25-29 years). The youth from the age group 25-29 years represent highest employability in high-skill occupation, followed by the employability of 20 24 and 15-19 years youth in the medium- and low-skill occupations, respectively, for the year 2011-2012. The employability of 25-29 and 20-24 years aged youth in the high-skill occupation has been observed to increase by $2.7 \%$ points and $2.1 \%$ points, respectively, during the study period (2011-2012 to 2017-2018). However, employability of 15-19 years aged youth in the low-skill occupation reflects a decline of $6.5 \%$ points during the same. Surprisingly, the female youth reflects $1.1 \%$ points and $6.9 \%$ points higher employability in

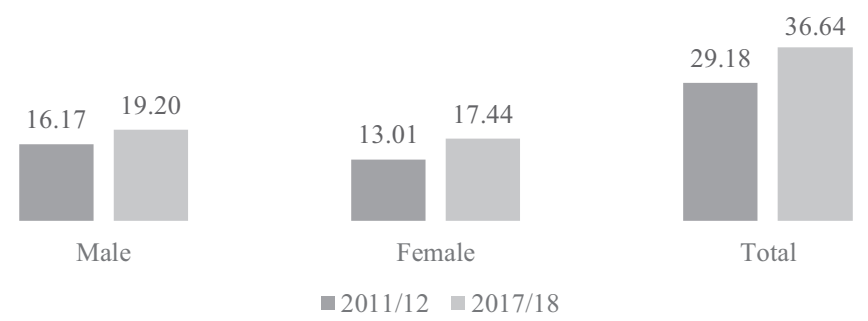

Source(s): Authors' computation from All India Survey on Higher Education

\section{Choices of educational attainment}

133
Figure 2.

Enrolment of youth in higher education across gender (in millions) 
JED
23,2

\begin{tabular}{|c|c|c|c|c|c|c|c|c|c|}
\hline \multirow{2}{*}{\multicolumn{2}{|c|}{ Characteristics }} & \multicolumn{4}{|c|}{ 2011-2012 } & \multicolumn{4}{|c|}{ 2017-2018 } \\
\hline & & $\begin{array}{l}\text { High } \\
\text { skill }\end{array}$ & $\begin{array}{l}\text { Medium } \\
\text { skill }\end{array}$ & $\begin{array}{l}\text { Low } \\
\text { skill }\end{array}$ & Total & $\begin{array}{l}\text { High } \\
\text { skill }\end{array}$ & $\begin{array}{l}\text { Medium } \\
\text { skill }\end{array}$ & $\begin{array}{l}\text { Low } \\
\text { skill }\end{array}$ & Total \\
\hline \multirow[t]{3}{*}{ Age } & 15-19 years & 5.2 & 56.3 & 38.6 & 19.1 & 4.7 & 63.2 & 32.1 & 13.7 \\
\hline & 20-24 years & 9.6 & 57.5 & 32.9 & 36.4 & 11.7 & 61.3 & 27.0 & 34.8 \\
\hline & $25-29$ years & 14.2 & 54.4 & 31.4 & 44.6 & 16.9 & 56.3 & 26.8 & 51.5 \\
\hline \multirow[t]{2}{*}{ Gender } & Male & 10.5 & 56.1 & 73.6 & 33.4 & 12.0 & 60.1 & 27.9 & 79.3 \\
\hline & Female & 11.6 & 55.4 & 33.0 & 26.4 & 18.9 & 54.5 & 26.6 & 20.8 \\
\hline \multirow[t]{2}{*}{ Sector } & Rural & 5.3 & 55.6 & 39.0 & 72.8 & 7.7 & 59.9 & 32.4 & 70.9 \\
\hline & Urban & 25.4 & 56.6 & 18.1 & 27.2 & 27.3 & 56.8 & 15.9 & 29.1 \\
\hline General & Illiterate & 2.4 & 46.9 & 50.8 & 17.2 & 2.0 & 54.3 & 43.7 & 10.7 \\
\hline \multirow[t]{4}{*}{ education } & $\begin{array}{l}\text { Literate up to } \\
\text { primary }\end{array}$ & 3.7 & 52.2 & 44.1 & 25.9 & 3.4 & 56.5 & 40.1 & 18.6 \\
\hline & $\begin{array}{l}\text { Up to higher } \\
\text { secondary }\end{array}$ & 9.2 & 63.3 & 27.5 & 46.3 & 8.8 & 64.5 & 26.7 & 54.8 \\
\hline & $\begin{array}{l}\text { Diploma/ } \\
\text { certificate course }\end{array}$ & 31.1 & 63.3 & 5.3 & 2.0 & 36.3 & 55.7 & 8.0 & 2.0 \\
\hline & $\begin{array}{l}\text { Graduation and } \\
\text { above }\end{array}$ & 52.4 & 43.4 & 4.2 & 8.7 & 50.7 & 44.5 & 4.8 & 13.9 \\
\hline \multirow[t]{3}{*}{$\begin{array}{l}\text { Technical } \\
\text { education }\end{array}$} & $\begin{array}{l}\text { No technical } \\
\text { education }\end{array}$ & 9.1 & 56.4 & 34.5 & 96.3 & 11.0 & 60.2 & 28.8 & 95.0 \\
\hline & Technical degree & 89.2 & 8.5 & 2.4 & 0.6 & 75.1 & 22.8 & 2.2 & 2.2 \\
\hline & Diploma below & 38.3 & 57.5 & 4.3 & 2.3 & 38.9 & 54.0 & 7.1 & 2.1 \\
\hline
\end{tabular}

graduation:

agriculture/

engineering/

technology/

medicine/crafts/

other subjects

$\begin{array}{lllllllll}\text { Diploma above } & 73.9 & 24.8 & 1.4 & 0.9 & 78.2 & 19.7 & 2.1 & 0.7\end{array}$

graduation:

agriculture/

engineering/

technology/

medicine/crafts/

other subjects

Vocational

Received forma

education

vocational/

technical training

Received non-

formal vocational/

20.7

6.8

$4.1 \quad 44.2$

48.4

7.4

3.1

technical

training\#

Did not receive

vocational training

Regions

Central

Eastern

North-eastern

Northern

Southern

Western

$\begin{array}{llllllll}9.1 & 70.3 & 20.7 & 15.2 & 9.4 & 69.7 & 20.9 & 12.6\end{array}$

Table 1.

Distribution of youth employed in a different category of occupations ( high/ medium/low skilled) with level of

Total

$\begin{array}{rrrrr}9.9 & 53.1 & 37.1 & 80.6 & 12.9 \\ 6.8 & 58.9 & 34.3 & 25.1 & 8.5 \\ 9.6 & 52.9 & 37.6 & 19.1 & 10.4 \\ 8.6 & 61.1 & 30.3 & 2.7 & 11.0 \\ 11.5 & 58.1 & 30.4 & 14.0 & 11.4 \\ 13.6 & 55.0 & 31.4 & 22.0 & 21.1 \\ 14.1 & 53.4 & 32.5 & 17.2 & 17.9 \\ 10.8 & 55.9 & 33.3 & 100.0 & 13.4\end{array}$

$\begin{array}{rrr}57.8 & 29.4 & 84.3 \\ & & \\ 61.0 & 30.5 & 27.4 \\ 56.7 & 33.0 & 19.2 \\ 64.4 & 24.6 & 3.0 \\ 65.8 & 22.8 & 14.2 \\ 53.0 & 25.9 & 20.8 \\ 58.9 & 23.2 & 15.4 \\ 59.0 & 27.6 & 100.0\end{array}$

Note(s): \#non-formal include self-learning/learning on the job/others

educational attainment (in percent)

Source(s): Authors' computation from National Sample Survey rounds on employment and unemployment, 2011-2012, and PLFS, 2017-2018 
high-skill occupation as compared to the male counterparts during the years 2011-2012 and 2017-2018, respectively. Throughout the study period, the employability of female youth in the high-skill occupation has shown an increase of $7.3 \%$ points. The employability of male youth finds their dominance in the medium- and low-skill occupations. Comparatively, in the urban sector, the youth find their employability dominance in the high-skill occupation and reflect a wide disparity. The urban youth reflect $20.1 \%$ points and $19.6 \%$ points higher inequality in high-skill occupation as compared to their rural counterparts for the years 20112012 and 2017-2018, respectively.

The employability of graduate and above youth portrays a decline of $1.7 \%$ points in the high-skill occupation during 2011-2012 and 2017-2018. The employability of youth in highskill occupation reflects a decline across all the levels of the educational hierarchy of general education. This phenomenon centralizes the key argument of this study that "does the educated youth lacks the essential skills to meet the suitability of the labour market in India". The youth with education up to higher secondary dominates the employability in medium-skill occupation and reflects an increase of $1.2 \%$ points during the study period. As expected, the low-skill occupation is dominated by the illiterate youth, followed by the youth with education up to the primary level. Apart, for the youth with graduation and above and diploma/certificate course, the low-skill occupation also highlights a decline across the educational hierarchy during 2011-2012 to 2017-2018. The increase of employability by $1.1 \%$ points in medium-skill occupation and $0.6 \%$ points in low-skill occupation for the youth with graduation and above reflects the mobility of educated youth in the underqualified occupation. The plausible reasons might be skill mismatch, shrinking employment opportunities and the growing share of NEET youth.

During 2011-2012 to 2017-2018, the employability in high-skill occupation for the technical degree youth declined by $14.1 \%$ points. In comparison, for the medium-skill occupation, it increased by $14.3 \%$ points during the same. The study observes a rise of $9.8 \%$ points youth employability in the high-skill occupation for the youth hailing from vocational education throughout the study period. The youth with informal vocational education dominates the medium-skill occupation, whereas the low-skill occupation remains the significant employment source for the youth who did not receive any vocational training. The southern region youth dominate the high-skill occupation employability, followed by the western region for the year 2017-2018. The employability of the southern region highlights an increase of $7.5 \%$ points during the study period. Due to better educational infrastructure, the southern region youth portray $12.6 \%$ points higher employability as compared to the central region counterparts for the year 2017-2018.

\subsection{Youth unemployability: diverse by education, collective by unemployment}

The growing unemployment amongst the educated youth (unsuccessful/delayed school-towork transition) marks a burden on the economic productivity of the nations (ILO, 2020). The study observes a drastic increase in the unemployment rate of the youth hailing from general education background during 2011-2012 to 2017-2018 (see Figure 3). The findings highlight an increase in the unemployment rate across the categories of general education during the same. The unemployment rate amongst the graduate and above youth portrays a rise of $16.2 \%$ points during $2011-2012$ to $2017-2018$. However, the study observes the highest increase of $21.0 \%$ points unemployment rate for the youth with diploma/certificate course during the same. On the contrary, youth with education up to the primary reflects the lowest increase of $5.3 \%$ points unemployment rate.

The familiar axiom regarding technical education is "better employability opportunities as compared to general education" - the reason being more comprehensive chances for

\section{Choices of educational attainment}


JED

23,2

136

acceptability of skills gathered through the technical courses. However, for youth with a technical degree, the study reflects $19.8 \%$ points higher unemployment rate as compared to the non-technical counterparts for the year 2017-2018 (see Figure 4). The higher unemployment rate for the technically educated youth highlights that even technical degree holders are not able to sustain their employability. The possible argument for the lower unemployment rate amongst the youth with no technical education might be the lack of technical skills, reflecting into higher employability opportunities in low skilled and precarious jobs. The study observes the highest increase of $20.3 \%$ points unemployment rate for the youth having diploma above graduation in agriculture/engineering/technology/ medicine/crafts/other subjects during the study period.

Over the study period, specific measures were initiated by the Government of India to promote the vocational courses amongst the youth. However, the study observes $14.0 \%$ points higher unemployment rate for the youth with formal vocational training as compared to the youth who did not receive vocational training for the year 2017-2018 (see Figure 5). The youth who received vocational training from non-formal sources (selflearning/learning on the job/others) reflect the lowest unemployment rate. The possible argument might be the availability of employability in specific trades/occupations (family/ traditional work).

\subsection{Assessment of the relative contributions of educational attainment affecting the youth employability}

Visualizing the magnitude of youth (un)employability, it is indispensable to address the extent to which individual level of educational attainment has influenced the youth employability in a different category of occupations (high/medium/low skilled). The study highlights an increase in the probability of employability in high-skill occupation with an increase in the age of youth during 2011-2012 to 2017-2018 (see Table 2). Significantly, 2529 years aged youth reflect an increase in the probability of employability in high-skill occupation from $4.7 \%$ (2011-2012) to $6.0 \%$ (2017-2018) regarding the reference base category of 15-19 years aged youth. The reason being completion of the highest education in the Indian context by the age of 25-29 years enable the younger generation to set the high-skill occupation as their utmost priority. Subsequently, the probability of employment in middle- and low-skill occupations reduces with an increase in age. The likelihood of female employability in the high-skill occupation reflects a significant increase from $3.1 \%$ (2011-2012) to $8.6 \%$ (2017-2018), concerning the omitted base category of male counterparts. However, the employment probability in the medium- and low-skill occupations declines for the female youth in the year 2017-2018. The decent work

Figure 3.

Distribution of youth unemployment rate across the general education (in percent)

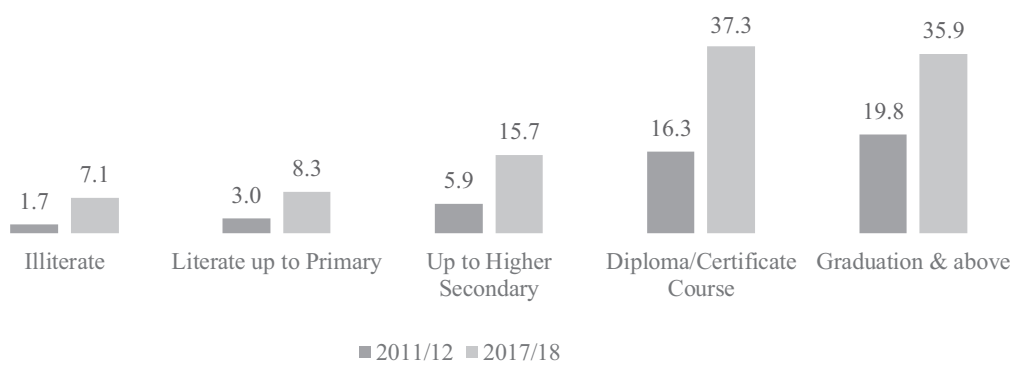

Source(s): Authors' computation from National Sample Survey rounds on employment and unemployment, 2011/12 and PLFS, 2017/18 
condition remains a concern amongst the female youth and restricts their employability in the medium- and low-skill occupations. The Indian labour market is blamed for functioning biasedly, based on the limited employability opportunities in the rural sector (Papola and Sahu, 2012). The same is the case with the youth labour market, where the employment probability of urban youth in the high-skill occupation highlights an increase from $9.4 \%$ (2011-2012) to $10.5 \%$ (2017-2018) regarding the omitted base category of the rural sector. However, the employment probability amongst the urban youth in case of medium- and low-skill occupations has significantly declined by 2.9 and $6.5 \%$, respectively, during $2011-$ 2012 to $2017-2018$.

To encompass that whether educational choices and their attainment level serve as the opportunity or risk factor towards youth employability, the study has narrowed down the edification into three broader categories of general, technical and vocational education. For general education, it has been observed that with an increase in the educational hierarchy of the youth, the probability of employment in high-skill occupation increases. With reference to the omitted base category of the illiterate younger generation, the youth with graduation and above showcase highest probability of 37.5\% (2011-2012) and 36.7\% (2017-2018) followed by the youth with the educational background of diploma and certificate course $30.2 \%$ (20112012 ) and $29.3 \%$ (2017-2018) towards employability in the high-skill occupation. The youth with the educational level of higher secondary reflect significant highest employment probabilities in the medium-skill occupation 15.6\% (2011-2012) and 10.6\% (2017-2018). Significantly, the employability likelihood reduces across all the levels of general education for the low-skill occupation.

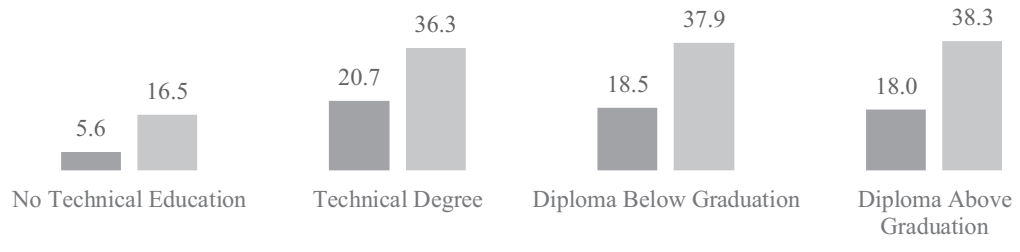

Agriculture/Engineering/Technology/Medicine/Crafts/Other Subjects

-2011/12 $\because 2017 / 18$

Source(s): Authors' computation from National Sample Survey rounds on employment and unemployment, 2011/12 and PLFS, 2017/18

\section{Choices of educational attainment}

Figure 4.

Distribution of youth unemployment rate across the technical education (in percent)

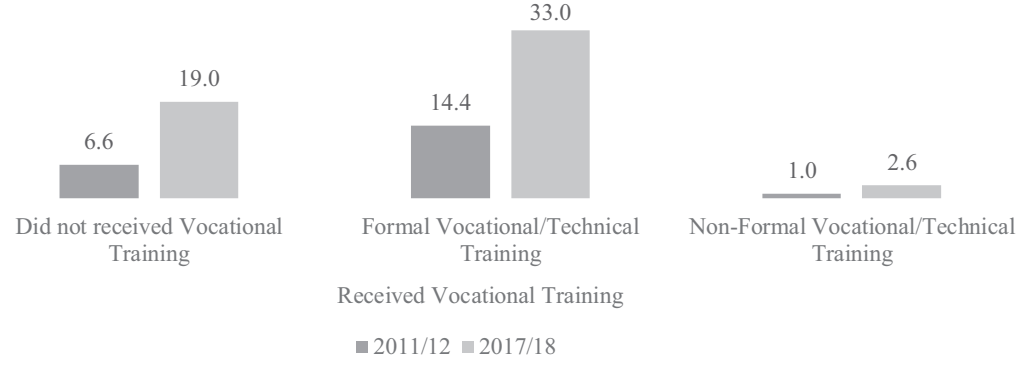

Source(s): Authors' computation from National Sample Survey rounds on employment and unemployment, 2011/12 and PLFS, 2017/18
Figure 5.

Distribution of youth unemployment rate across vocational education (in percent) 


\begin{tabular}{l} 
JED \\
23,2 \\
138 \\
\hline
\end{tabular}

Table 2.

Relative contributions of educational attainment affecting employability amongst the youth in India (estimates of multinomial logit model with marginal effects)

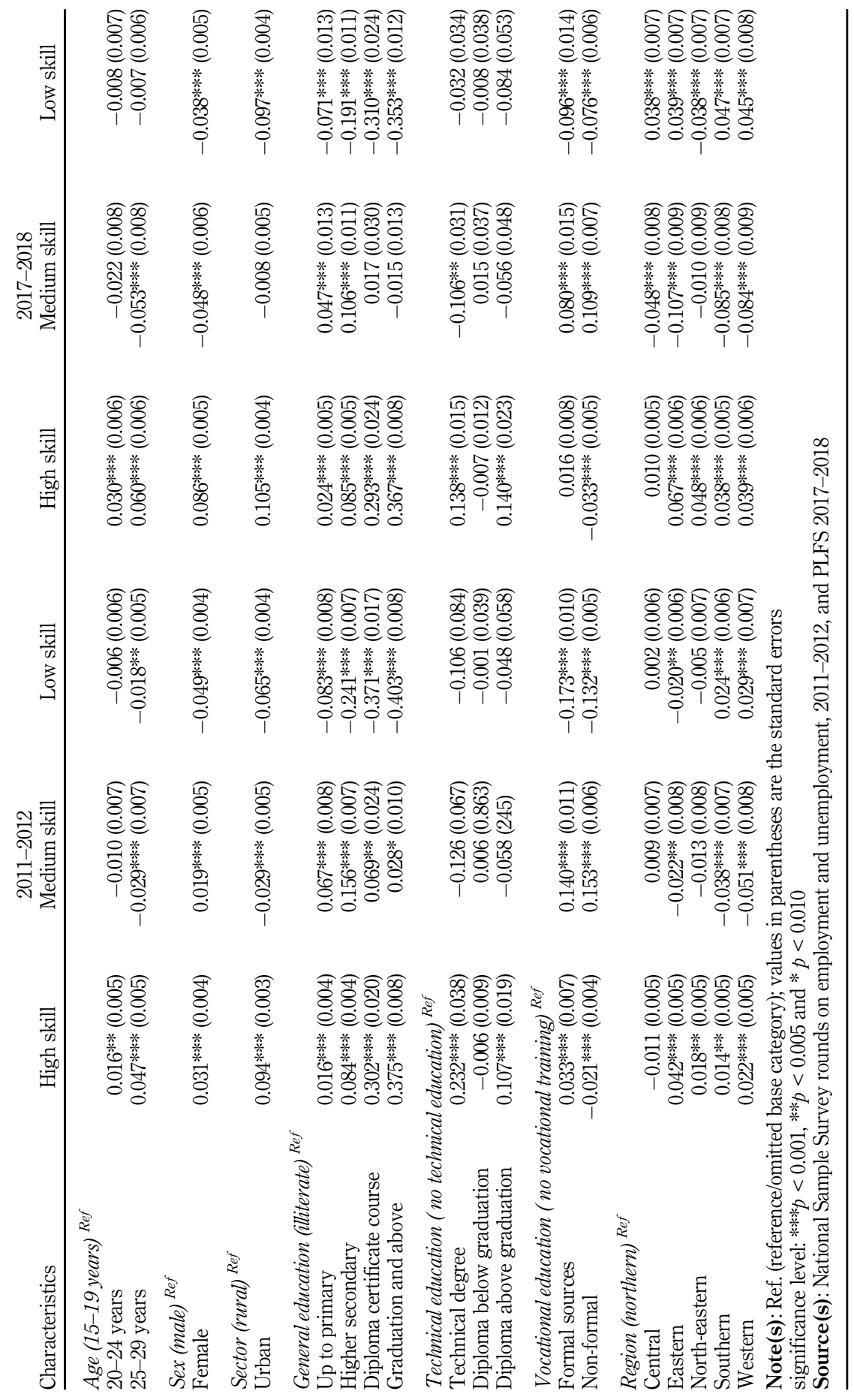


The technically educated youth enjoys an upper hand in terms of employability opportunities as compared to the non-technical counterparts. Secondly, the youth hailing from technical education resembles lower chances of being overeducated as compared to their general education counterparts in the labour market (Chevalier, 2003). For the youth with a technical degree, the employment opportunities in the high-skill occupation reflect $23.2 \%$ probability for the year 2011-2012 as compared to the omitted base category of non-technical youth. However, for the year 2017-2018, the employability probability has reduced for the technical degree holders $(13.8 \%)$. Subsequently, the youth with diploma above graduation reflects significant employability probability of $10.7 \%$ (2011-2012) and 14.0\% (2017-2018) towards the high-skill occupation. The study has observed a decline in the employability probability towards mediumand low-skill occupations for both the technical degree and diploma above graduation youth. The employability in the medium-skill occupation has declined (Kolev and Saget, 2010) due to "hollowing out hypothesis", which increases the demand for high- and low-skill occupations (Acemoglu and Autor, 2011). For the youth with diploma below graduation, the employability probability has declined significantly for the high-skill occupation. However, the same remains non-significant for the medium- and low-skill occupations.

Vocational education serves as the proxy for skills (Mehrotra et al., 2013). The employment probabilities in the high- and low-skill occupations have significantly reduced for the youth who received vocational training from non-formal sources (self-learning/learning on the job/ others). Studies have observed vocational education as a high-risk factor towards youth employability due to the inability of the vocational education to meet the fast upgrading and continuous changing demand of the labour market (ILO, 2020). However, for the medium-skill occupation, their employability probability highlights a significant increase of $15.3 \%$ (20112012 ) and $10.9 \%$ (2017-2018). Contemporarily, the youth who have received vocational training from formal sources reflect $3.3 \%$ employability likeliness in the high-skill occupation for the year 2011-2012. For the medium-skill occupation, the probability of employment has increased by $14.0 \%$ (2011-2012) and 8.0\% (2017-2018), while it reduced for the low-skill occupation.

The states in India reflect their own sociocultural and demographic identity, causing a base for the disparity in the employability opportunities in the labour market. However, to estimate the broader aspect of regional differences prevalent in the youth labour market functioning, this study attempts to reduce the individual state-specific effect by standardizing and forming regions based on common sociocultural characteristics. Considering the northern region as the omitted base category, it has been observed that, a significant likeliness of 4.2\% (2011-2012) and 6.7\% (2017-2018) employability in the high-skill occupation prevails for the youth from the eastern region. While for the medium- and low-skill occupations, the employability probabilities have reduced during the same. The southern region is marked by high educational enrolment and reflects significant probability towards employability in high-skill occupation by $1.4 \%$ (20112012 ) and 3.8\% (2017-2018). Subsequently, the western region is considered to be the centre of economic growth in India and portrays the employment probabilities of 2.2\% (2011-2012) and $3.9 \%$ (2017-2018) in the high-skill occupation.

\section{Conclusions}

The study has attempted to highlight the role of specific educational choices/attainments as an opportunity or a challenge in deriving the skill-specific employability of the youth in India. The growing enrolment of both the male and female youth in higher education indicates the brighter prospects for the country. With the educational expansion, the educational choices for the younger generation have also leapt forward. The findings implicate the bulge of youth workforce employability in the medium-skill occupation indicating the "crowding out" effect. The increase of overall employability noted for the high- and middle-skill occupations reflects

\section{Choices of educational attainment}


JED

23,2

140

the improvised occupational mobility of the younger generation. However, the decline of overall employability in the low-skill occupation raises a threat to the inclusive approach of the economy as such youth remain economically inactive and thereby raising the NEET proportion. There might be a possibility that the government initiatives over the study period towards skilling and re-skilling have resulted in upward occupational mobility. However, the effect of general educational choice on increasing the youth employability is restricted to medium-skill occupation only. The pattern reflects the limited employability opportunities for the youth hailing from general education. The drastic increase of technical degree holder youth in the medium-skill occupation indicates the skill mismatch. Due to skill mismatch, the technical youth are forced to compensate with the under-skilled occupation. Comparatively, vocational education from formal sources reflects increasing employability in the high-skill occupation. Concluding, the educational choices does not mark a powerful effect on increasing the skill-specific youth employability. The high unemployment rate amongst the educated that too amongst the highest degree holders in both the general and technical education highlights the missing link between the existing educational outcome and the labour market functioning.

The study recommends the promotion of vocational and on-the-job training to secure the employability of the youth in India. The formal sources of vocational training need more strengthening through collaboration with the enterprises to remove the skill deficit of the youth labour market. Investment on promoting the acceptability of vocational education amongst the youth and society will enhance the youth employability through market-driven relevant skills. Doing so will be a preparatory step to tackle the future challenge of automation, which is believed to worst-hit the youth employability. However, the Government of India has initiated specific measures over the last decade to enhance the youth employability and tackle the challenge of skill mismatch. The importance of skill is envisaged through the National Vocational Education Quality Framework (NVEQF), which aims to skill the $500 \mathrm{~m}$ workforces by the year 2022, by providing easy mobility between the general education and the vocational courses.

Therefore, the step towards the vocational education system may result in tackling the growing challenge of NEET youth in the Indian context. However, to meet the fast-changing dynamics of the labour market, vocational education needs to upgrade on a timely basis. Moreover, to enable the youth towards decent employability, the general and technical education needs to equip with apprenticeship and industrial training in the labour market to gain relevant work experience as a part of the educational curriculum. The significant effect of regional disparity calls for the adoption of state-specific skill definition. The diversity of Indian states does not allow us to follow the "one-size-fits-all" approach; therefore, statespecific, sector-specific market-linked education, skill enhancement training and programmes needs to be developed to meet the greater challenge of enabling the youth towards employability. Timely initiative in this direction will enhance the youth employability in the short run. While in the long run, an economically active youth will contribute to economic development.

\section{References}

Acemoglu, D. and Autor, D. (2011), "Skills, tasks and technologies: implications for employment and earnings", Handbook of Labor Economics, Vol. 4, pp. 1043-1171.

Agarwal, P. (2008), "Higher education and the labor market in India", in Lin, J.Y. and Pleskovic, B. (Eds), Higher Education and Development, Annual World Bank Conference on Development Economics Regional 2008, The World Bank, Washington, DC, pp. 245-271.

Aggarwal, A. and Gasskov, V. (2013), Comparative Analysis of National Skills Development Policies: A Guide for Policy Makers, International Labour Organization, Geneva. 
Arrow, K.J. (1973), "Higher education as a filter", Journal of Public Economics, Vol. 2 No. 3, pp. 193-216.

Artess, J., Mellors-Bourne, R. and Hooley, T. (2017), "Employability: a review of the literature 20122016", A Report for the Higher Education Academy, Higher Education Academy, pp. 1-52.

Bhanwala, K.H. and Mani, G. (2020), "Engaging rural youth gainfully", Economic and Political Weekly, Vol. 55 No. 11, pp. 16-18.

Bisht, N. and Pattanaik, F. (2020), "Youth labour market in India: education, employment, and sustainable development goals", in Amine, S. (Ed.), International Perspectives on the Youth Labor Market: Emerging Research and Opportunities, IGI Global, pp. 172-196.

Brennan, J. (1996), Higher Education and Work. Higher Education Policy Series, Jessica Kingsley Publishers, Bristol, PA, Vol. 23.

Brooks, A. (1997), Academic Women, Society for Research into Higher Education, Buckingham.

Brown, P., Hesketh, A. and Wiliams, S. (2003), "Employability in a knowledge-driven economy", Journal of Education and Work, Vol. 16 No. 2, pp. 107-126.

Chevalier, A. (2003), “Measuring over-education”, Economica, Vol. 70 No. 279, pp. 509-531.

Chevalier, A. and Lindley, J. (2009), "Overeducation and the skills of UK graduates", Journal of the Royal Statistical Society: Series A, Vol. 172 No. 2, pp. 307-337.

Denny, K. and Harmon, C. (2000), "The impact of education and training on the labour market experiences of young adults", No. W00/08. IFS Working Papers.

Dev, S.M. and Venkatanarayana, M. (2011), Youth Employment and Unemployment in India, Indira Gandhi Institute of Development Research, Mumbai.

Dibeh, G., Fakih, A. and Marrouch, W. (2019), "Employment and skill mismatch among youth in Lebanon", International Journal of Manpower, Vol. 40 No. 8, pp. 1438-1457.

Dunne, E., Bennett, N. and Carre, C. (2000), "Skill development in higher education and employment", Differing Visions of a Learning Society: Research Findings, Vol. 1, pp. 105-137.

Fasih, T. (2008), "Linking education policy to labor market outcomes", The World Bank, pp. 1-108.

Guilbert, L., Bernaud, J.L., Gouvernet, B. and Rossier, J. (2016), "Employability: review and research prospects", International Journal for Educational and Vocational Guidance, Vol. 16 No. 1, pp. 69-89.

Hansson, B. (2007), "Effects of tertiary expansion: crowding-out effects and labour market matches for the higher educated", OECD Education Working Papers, No. 10, OECD Publishing (NJ1), doi: 10.1787/085513474523.

Hillage, J. and Pollard, E. (1998), Employability: Developing a Framework for Policy Analysis, DfEE, London, Vol. 107.

ILO (2020), Global Employment Trends for Youth: Technology and Future of Jobs, available at: https:// www.ilo.org/global/publications/books/WCMS_737648/lang-en/index.htm.

Kolev, A. and Saget, C. (2010), Are Middle-Paid Jobs in OECD Countries Disappearing? An Overview, ILO, Geneva.

Krishnakumar, J. and Nogales, R. (2020), "Education, skills and a good job: a multidimensional econometric analysis", World Development, Vol. 128, p. 104842.

Kucharski, L. and Kwiatkowski, E. (2006), "Multinomial logit model and its application in labour market position analysis of individuals in Poland", Folia Oeconomica, Vol. 196, pp. 199-207.

Kyndt, E. and Baert, H. (2013), “Antecedents of employees' involvement in work-related learning: a systematic review”, Review of Educational Research, Vol. 83 No. 2, pp. 273-313.

Mahapatro, S. (2019), "Female employment in India: determinants of choice of sector of activity", Journal of Economic Studies, Vol. 46 No. 3, pp. 748-759.

McQuaid, R.W. and Lindsay, C. (2005), “The concept of employability”, Urban Studies, Vol. 42 No. 2, pp. 197-219. 
JED

23,2

142

Mehrotra, S., Gandhi, A. and Sahoo, B.K. (2013), "Estimating India's skill gap: on a realistic basis for 2022", Economic and Political Weekly, Vol. 48 No. 13, pp. 102-111.

MHRD (2019), All India Survey on Higher Education 2018-2019, Ministry of Human Resource and Development, New Delhi, available at: http://aishe.nic.in/aishe/reports.

Mitra, A. and Verick, S. (2013), Youth Employment and Unemployment: An Indian Perspective, International Labour Organization, Geneva.

Okada, A. (2012), "Skills development for youth in India: challenges and opportunities", Journal of International Cooperation in Education, Vol. 15 No. 2, pp. 169-193.

Papola, T.S. and Sahu, P.P. (2012), Growth and Structure of Employment in India, Institute for Studies in Industrial Development, New Delhi.

Pool, L.D. and Sewell, P. (2007), "The key to employability: developing a practical model of graduate employability", Education + Training, Vol. 49 No. 4, pp. 277-289.

Poterba, J.M. and Summers, L.H. (1995), "Unemployment benefits and labor market transitions: a multinomial logit model with errors in classification", The Review of Economics and Statistics, Vol. 77 No. 2, pp. 207-216.

Purcell, K., Pitcher, J. and Simm, C. (1999), Working Out?: Graduates' Early Experiences of the Labour Market, CSU (Publications) Limited, London.

Sanghi, S. (2012), "Skill development for employability", Vikalpa, Vol. 37 No. 3, pp. 89-94.

Sharma, S. and Sharma, P. (2017), "Educational mismatch and its impact on earnings: evidence from Indian labour market”, International Journal of Social Economics, Vol. 44 No. 11, pp. 1778-1795.

Singh, C.S.K. (2003), "Skill, education and employment: a dissenting essay", Economic and Political Weekly, Vol. 38 No. 31, pp. 3271-3276.

Smith, J., McKnight, A. and Naylor, R. (2000), "Graduate employability: policy and performance in higher education in the UK", The Economic Journal, Vol. 110 No. 464, pp. 382-411.

Taylor, A. I (2005), "What employers look for: the skills debate and the fit with youth perceptions", Journal of Education and Work, Vol. 18 No. 2, pp. 201-218.

Tilak, J.B. (2015), "How inclusive is higher education in India?", Social Change, Vol. 45 No. 2, pp. 185-223.

Wheebox (2020), India Skills Report 2020: Reimagining India's Talent Landscape for a \$5t Economy, India, available at: https://wheebox.com/india-skills-report.htm.

Wooldridge, J.M. (2002), Econometric Analysis of Cross Section and Panel Data, MIT Press, Cambridge, MA, p. 108.

\section{Further reading}

Agrawal, T. (2014), "Skill development in India: an examination", Journal of Education and Work, Vol. 27 No. 6, pp. 629-650.

Ministry of Statistics and Programme Implementation, Government of India (2014), Employment and Unemployment Situation in India 2011-2012, Sixty Eighth Round, July 2011-June 2012, Report No. 554, National Sample Survey Office, New Delhi.

Ministry of Statistics and Programme Implementation, Government of India (2019), Periodic Labour Force Survey, July 2017-June 2018, May 2019, National Statistical Office, New Delhi.

\section{About the authors}

Nitin Bisht is working as a research scholar in the Department of Humanities and Social Sciences at the the Indian Institute of Technology, Roorkee. His research interests lie in the fields of development economics, labour economics, especially the dynamics of youth labour market in India. Before joining as a research scholar, he had the experience of working in the development sector with international 
organizations such as the United States Agency for International Development (USAID) and the World Bank. Nitin Bisht is the corresponding author and can be contacted at: bisht.nitin4@gmail.com

Professor Falguni Pattanaik is working in the capacity of assistant professor at the Department of Humanities and Social Sciences at the Indian Institute of Technology, Roorkee. His research interests lie in the fields of development economics, labour economics and macroeconomics. He is interested in analysing the theoretical and applied macroeconomic aspects of economic development, such as issues related to growth, employment and poverty. He has published his research papers in the journals of national and international repute, i.e. Margin: The Journal of Applied Economic Research, Journal of the Asia Pacific Economy and Journal of the Asia Pacific Economy.

\section{Choices of educational attainment}

For instructions on how to order reprints of this article, please visit our website: www.emeraldgrouppublishing.com/licensing/reprints.htm Or contact us for further details: permissions@emeraldinsight.com 